\title{
Conflitos éticos no cuidado domiciliar: o dilema dos enfermeiros
}

Recebido em: 26/11/2011

Aceito em: 16/04/2012
Ramone Aparecida Przenyczka ${ }^{1}$ Maria Ribeiro Lacerda² Mariluci Alves Maftum ${ }^{3}$

O estudo adotou a Teoria Fundamentada nos Dados como método e foi realizado com 21 enfermeiros atuantes no cuidado domiciliar. Objetivou-se desenvolver um modelo teórico sobre os conflitos éticos no cuidado domiciliar. Os resultados apontaram para o modelo teórico "família consensual" e, entre os conflitos referidos, incluíram-se as questões sobre a competência e o sigilo profissional, a violência, a capacitação do cuidador. Concluiu-se que importantes conflitos ocorrem no domicílio e que são necessários novos estudos sobre o tema para apontar situações diversas e igualmente relevantes.

Descritores: Enfermagem, Assistência Domiciliar, Ética.

\section{Ethical conflicts in home care: the dilemma of nurses}

The study adopted the Grounded Theory as methodology, and it was conducted with 21 nurses working in home care. The objective was to develop a theoretical model contemplating the ethical conflicts in home care. The results pointed to the theoretical model "consensus family" and among referring conflicts, it was included questions about the professional competence and the professional confidentiality, the violence, the training of caregivers. Concluding, significant conflicts are experienced in home care and further studies on the subject are necessary to point many situations equally relevant.

Descriptors: Nursing, Home Nursing, Ethics.

\section{Conflictos éticos en la atención de salud domiciliaria: el dilema de los enfermeros}

El estudio adotó la Teoría Fundamentada en los Dados como método y fue realizado con 21 enfermeros que trabajan en la atención domiciliaria. El objetivo fue desarrollar un modelo teórico de conflictos éticos en la atención domiciliaria. Los resultados apuntaron para el modelo teórico "consenso de la familia" y, entre los conflictos, se incluyen preguntas sobre competéncia y secreto profesional, la violéncia, la formación de los cuidadores. Se concluyó que importantes conflictos ocurren en la atención domiciliaria y que se necesitan más estúdios sobre el tema para señalar muchas situaciones igualmente relevantes.

Descriptores: Enfermería, Atención de Salud Domiciliaria, Ética.

\section{INTRODUÇÃO}

$\mathrm{H}$ odiernamente, faz-se necessário considerar as questões éticas relacionadas às demandas de saúde, pois, afinal, o processo saúde-doença não deve ser abordado somente por seus aspectos biologicistas. Tais questões éticas podem evoluir para um conflito ou dilema ético.

Um conflito significa ocorrência concomitante de exigências antagônicas e mutuamente excludentes ou o ato, estado ou efeito de divergir ou de se opor duas ou mais coisas. Já o dilema ocorre quando há necessidade de escolha entre opções opostas A e B, que resultará em uma conclusão $C$, que se origina necessariamente tanto de $A$ quanto de $B^{(1)}$.

O conflito ético tratado neste artigo diz respeito a uma colisão entre determinada ação ou omissão do profissional, do paciente ou de sua família e a ética. O dilema ético, por seu turno, acontece entre duas opções envolvem uma situação ética. Assim, o profissional está diante de mais de um caminho e tem de optar por um deles; nessa perspectiva, pode-se afirmar que ele possui um conflito entre duas ou mais possibilidades.

Assim, versar-se-á sobre o conflito, doravante, como um termo genérico que abrange o dilema, sendo que esse é um conflito particular que envolve, necessariamente, uma escolha.

É fato que a enfermagem domiciliar está crescendo e com ela surge a necessidade de examinar o padrão ético relacionado. $O$ estudo da ética, na área da saúde, ainda é defectivo e, em maior grau, na enfermagem domiciliar.

Revisão sistemática sobre dilemas éticos mostrou que as publicações encontradas envolveram reanimação cardiopulmonar de paciente, hemotransfusão em Testemunhasde-Jeová, prática da enfermagem sem condições materiais, continuidade ou não do tratamento de pacientes com paralisia cerebral grave ${ }^{(2)}$. Não foram mencionados trabalhos sobre dilemas éticos no domicílio.

Desse modo, o objetivo desta pesquisa foi desenvolver um modelo teórico sobre os conflitos éticos no cuidado domiciliar

\section{METODOLOGIA}

Este estudo faz parte da dissertação apresentada ao programa de pós-graduação em enfermagem da UFPR. Optou-se por uma

1 Mestranda do PPGENF da UFPR. Enfermeira da prefeitura da Lapa/PR. Membro do Núcleo de Estudos, Pesquisa e Extensão em Cuidado Humano de Enfermagem (Nepeche) da UFPR. E-mail: przenyczka@yahoo.com.br.

2 Doutora em filosofia da enfermagem. Coordenadora do Nepeche. Professora do PPGENF/UFPR.

3 Doutora em enfermagem. Coordenadora do PPGENF/UFPR. Professora do PPGENF/UFPR. 
pesquisa qualitativa, que utilizou a Teoria Fundamentada nos Dados (TFD) ou Grounded Theory (GT).

A TFD é um método consistente para a realização de pesquisas cujo objeto de estudo envolve interações humanas, sendo uma promessa para o entendimento do conhecimento da enfermagem e um meio de gerar teorias ${ }^{(3)}$.

A amostragem teórica é formada por 21 enfermeiros, distribuídos em três grupos amostrais: $1^{\circ}$ ) nove enfermeiros de Unidades de Saúde (US) com Estratégia Saúde da Família (ESF) do município de Curitiba/PR; $2^{\circ}$ ) sete enfermeiros de instituições privadas de home care; $3^{\circ}$ ) cinco enfermeiros que atuam no cuidado domiciliar sem vínculo empregatício.

A coleta de dados foi realizada de outubro de 2010 a junho de 2011 por meio de entrevista semiestruturada e gravada em áudio.

As fases da análise englobam as codificações substantiva e teórica, que ocorrem simultaneamente. Na primeira, o pesquisador descobre os códigos dentro dos dados por meio da criação de conceitos e, na segunda, verifica como os códigos se relacionam entre si, elaborando hipóteses que serão integradas à teoria ${ }^{(4)}$.

$\mathrm{Na}$ codificação substantiva, foram elaboradas diferentes categorias, das quais foi contemplada, para este recorte, apenas uma, em razão de sua densidade. Trata-se da categoria central, "Reconhecendo os conflitos éticos em sentido amplo", representante do tema principal da pesquisa ${ }^{(4)}$.

$\mathrm{Na}$ codificação teórica, a partir da análise dos dados, enquadrou-se o fenômeno no código teórico "família consensual".

Seguiram-se as normas da resolução 196/96 do Conselho Nacional de Saúde, que envolvem as pesquisas com seres humanos. Houve aprovação da pesquisa pelo Comitê de Ética em Pesquisa da UFPR, sob o protocolo 0058.0.085.091-1.

\section{RESULTADOS}

O código "família consensual" comporta acordos, uniformidades, opiniões, conflitos, discordância e não conformidade. Importante aludir que a heterogeneidade dos elementos culturais pode levar à discordâncias, mas há

Gráfico 1 - Modelo teórico família consensual de "Conflitos éticos em sentido amplo no cuidado domiciliar"

Conflitos éticos em sentido amplo no cuidado domiciliar de Enfermagem

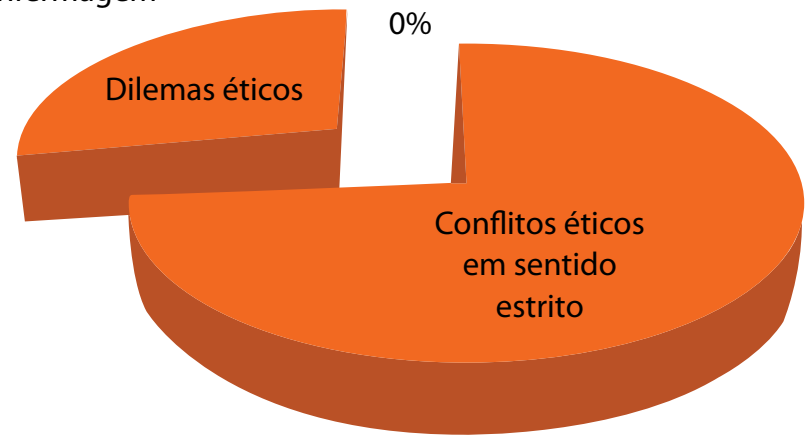

situações em que o consenso pode prevalecer ${ }^{(4)}$, motivo pelo qual se elegeu esse código.

A análise dos resultados evidenciou um consenso entre os entrevistados quanto aos conflitos e dilemas éticos vivenciados. Mas relembra-se que o consenso implica em sua antítese, como Glaser assevera(4), ou seja, outras pesquisas podem trazer informações e códigos diversos (gráfico 1).

Considerou-se que o termo "conflito" é genérico, o que significa ponderar que engloba um problema, uma situação e até um dilema ético. Assim, originou-se a nomenclatura "Conflitos éticos em sentido amplo", que abrange os "Conflitos éticos em sentido estrito" e os "Dilemas éticos", originários de subcategorias de mesmo nome.

"Conflitos éticos em sentido estrito" englobam situações éticas específicas que não evoluíram para um dilema. São situações que entram em choque com a ética, que deixam o profissional perplexo pela oposição ao que é compreendido como agir ético. Possui como componentes: "Extrapolando a competência profissional", "Violando o sigilo profissional", "Preconceito", "Violência", "Aborto" e "Morte”.

Em "Extrapolando a competência profissional", mencionase a transposição dos limites da competência profissional, momento em que o enfermeiro realiza o papel de outros profissionais.

O familiar ou o cuidador [...] pede para você indicar alguma medicação ou que você prescreva [...]. As pessoas querem que você tome o papel de outros profissionais que não the cabe [...]. (E11)

Quanto à "Violação do sigilo profissional", trata-se de uma questão ética bastante presente na prática dos profissionais. A quebra do sigilo profissional ocorre quando o enfermeiro revela as informações não só para o familiar do paciente como, também, para outros colegas ou em atividade acadêmica.

Sou professor e conto diversos casos de pacientes em sala de aula [...]. Claro que não falo o nome do paciente, [...] mas estou revelando segredo de um paciente que eu cuidei. Vai que um aluno sabe quem é o paciente, que, pela história, ele consegue saber quem é, nunca se sabe... (E19)

Um assunto de repercussão foi o preconceito praticado por alguns profissionais da enfermagem no cuidado domiciliar, exposto no componente "Preconceito". Tal desrespeito não é restrito à enfermagem, sendo cometido por outros profissionais.

Tanto no hospital quanto no domicílio tem muito preconceito, tem muito profissional [...] discriminando os pacientes. No hospital o profissional não tem como escolher o paciente, [...] mas no domicílio o enfermeiro pode [...] e, às vezes, ele escolhe mesmo e, assim, está discriminando [...]. (E18)

Mais um componente é a "Violência". A violência contra a criança foi bastante referida pelos sujeitos; aludiram-se eventos de abuso sexual, de agressão física, de abandono, de negligência, de prostituição infantil.

A gente teve um caso de uma criança que estava sendo molestada pelo vizinho e a gente encaminhou tudo o que precisava, mas a mãe era resistente. Ela sempre negava. (E1) Em "Aborto", percebeu-se que o mesmo foi manifestado, 
especialmente, por adolescentes. Além de uma situação ilegal, pode ocasionar riscos à saúde e vida das pacientes que utilizam medicamentos abortivos, cujos demais efeitos são desconhecidos.

E, por serem jovens, [...] o aborto é feito de qualquer jeito. Tomam um remédio que a vizinha falou e nem sabem o que pode acontecer com elas. O pior é quando não conseguem abortar e a criança nasce cheia de problemas. (E7)

Levantou-se mais um conflito disposto no componente "Morte". Apesar de o prognóstico "morte" ser inevitável, pacientes em sua iminência causam bastante expectativa aos cuidadores.

A família me pergunta muito sobre quando o paciente vai morrer. [...] Eles têm medo, têm preocupação, [...] não querem deixar aquela paciente ir. [...] Acham que podemos responder se falta muito tempo de vida ou não. (E19)

$\mathrm{Na}$ subcategoria "Dilemas éticos", que possui dois componentes, foram incluídos conflitos que levam os enfermeiros à dúvida sobre qual conduta seguir.

O primeiro componente, "Consentimento da família: a quem respeitar?", informa que o paciente está envolto por diversos familiares e, considerando seu estado de saúde, é importante que alguém assuma a responsabilidade por seu cuidado. $\mathrm{O}$ dilema surge quando há a interferência de vários familiares, cada um com um posicionamento diferente, e o enfermeiro deve definir qual consentimento seguir.

Cada filho te diz uma coisa e você não sabe o que fazer. Claro que opto por fazer o que é melhor para o paciente, mas é difícil. Um te dá consentimento para uma coisa, o outro não te dá, você fica maluca. (E14)

No segundo componente, "Capacitação do cuidador: qual o limite?", o enfermeiro vive um dilema porque tem de optar por ensinar ou não atividades da enfermagem aos cuidadores leigos.

Nós temos que capacitar o cuidador para os momentos em que nós não estamos ali. Mas até onde eu posso ir, o que eu posso ensinar? Eu não posso estar ali 24 horas [...]. E é um dilema ter que ensinar essas coisas, essas atividades que são nossas, que competem a nós. (E14)

\section{DISCUSSÃO}

Quanto ao componente "Extrapolando a competência profissional", o profissional que assume atividades de outrem está sujeito a ser enquadrado no exercício ilegal da profissão, conforme a Lei das Contravenções Penais ${ }^{(5)}$. Para exercer uma profissão, é preciso conhecimento científico, estudo e registro num Conselho Profissional que também atua como órgão fiscalizador(6).

Sobrea violação do sigilo profissional, depreende-sea importância do papel do enfermeiro na manutenção das informações do paciente em sigilo e na orientação da equipe sobre o tema.
Segundo o Código de Ética dos Profissionais da Enfermagem (Cepe), é dever dos profissionais "Manter segredo sobre fato sigiloso de que tenha conhecimento em razão de sua atividade profissional, exceto casos previstos em lei, ordem judicial ou com o consentimento escrito da pessoa envolvida ou de seu representante legal"(7).

Em "Preconceito", cita-se estudo realizado num pronto atendimento adulto de um hospital de Curitiba/PR que evidenciou a presença de preconceito e de rejeição dos profissionais de enfermagem em relação ao paciente com comorbidade clínico-psiquiátrica, o que se distancia do cuidado humanizado ${ }^{(8)}$.

Em "Violência", ressalta-se aquela praticada contra a criança. A situação torna-se mais preocupante porque, geralmente, o agressor está dentro do domicílio. Trabalho realizado com 278 crianças apresentou que a agressão psicológica ocorreu em $96,7 \%$ dos domicílios; o castigo corporal foi referido por $93,8 \%$ dos respondentes; e a violência física menor e a grave foram praticadas por $51,4 \%$ e $19,8 \%$ das famílias, respectivamente, sendo a mãe a principal autora ${ }^{(9)}$.

A seguir, tem-se o componente "Aborto". Deacordo comoCepe,é proibido "Provocar aborto ou cooperar em prática destinada a interromper a gestação"(7). O aborto só é permitido se não há outro meio de salvar a vida da gestante ou se a gravidez resulta de estupro ${ }^{(10)}$. Nessas condições, o Cepe faculta ao profissional decidir, de acordo com sua consciência, sobre sua participação no ato abortivo ${ }^{(7)}$.

Outro conflito ético diz respeito ao componente "Morte". Em algumas situações, o enfermeiro centra-se no cuidado técnico-científico, visando à cura daquele que está diante da morte. Nessa perspectiva, é importante o investimento em estudos sobre situações ligadas à família, à morte e ao morrer, o que favorecerá a construção de uma enfermagem mais humana e pronta para atuar em situações inerentes ao cuidado ${ }^{(11)}$.

O componente "Consentimento da família: a quem respeitar?" aclara que o consentimento informado é o registro de uma decisão voluntária por parte do paciente ou de seus responsáveis legais, tomada após um processo informativo e esclarecedor, para autorizar tratamento ou procedimento médico, consciente de seus riscos, benefícios e possíveis consequências ${ }^{(12)}$. Ressalva-se que o consentimento não é somente para procedimento médico e, sim, para o de todos os demais profissionais da área da saúde.

Quando o paciente está impossibilitado de fazê-lo, a incumbência de fornecer o consentimento cabe ao responsável legal. Não é rara a impossibilidade de obter o consentimento de um ou de ambos os genitores, considerando-se situações como divórcio com guarda compartilhada dos filhos, genitores omissos ou ausentes, abrigo do menor por membro da família expandida sem que tal guarda tenha sido legalmente estabelecida ${ }^{(12)}$. 
Sobre o consentimento do responsável pelo idoso, o que dificulta é que nem sempre ele possui um responsável legal definido. Nesse caso, o enfermeiro deve estar atento para escolhas que atendam ao paciente da melhor maneira.

Com relação ao componente "Capacitação do cuidador: qual o limite?", esclarece-se que o cuidado envolve a presença de um enfermeiro para classificar a complexidade do atendimento e a instabilidade de alguns estados de alterações fisiopatológicas ${ }^{(6)}$.

Um estudo explorou esse tema e, segundo os autores, para o familiar que não possui condições de contratar um profissional qualificado, é frequente o ensino de determinadas atividades da enfermagem para que seja dada continuidade aos cuidados. No entanto, o cuidador não possui o devido preparo e conhecimento, fato que pode acarretar prejuízos à saúde do paciente(13).

Ademais, cuidadores leigos não possuem habilitação legal para a prática da enfermagem e registro no respectivo Conselho, contrariando a lei $n^{\circ} 7498 / 86^{(14)}$. Por outro lado, o enfermeiro tem o dever de proporcionar a continuidade dos cuidados e está envolvido com a saúde e qualidade de vida das pessoas, como disposto no $\mathrm{Cepe}^{(7)}$.
Tal comprometimento se concretiza, também, pelo ensino do cuidador domiciliar, que dará continuidade aos cuidados do paciente, pois a enfermagem deve agir na recuperação e reabilitação da saúde ${ }^{(7)}$.

\section{CONSIDERAÇÕES FINAIS}

Observaram-se equívocos, por parte dos entrevistados, com relação ao correto entendimento do que é um dilema ético. Muitas situações éticas mencionadas como dilemas eram, na verdade, conflitos éticos, se observadas as definições adotadas.

Dos dados, insurgiram muitos conflitos, cuja discussão pode contribuir para a prática dos profissionais. Graves problemas estão ocorrendo no domicílio, muitos deles contrariando o Código de Ética dos Profissionais de Enfermagem e a legislação brasileira, sendo importantes maiores discussões sobre esse assunto.

Acrescenta-se que análises efetuadas por outros pesquisadores, com o mesmo objeto de pesquisa e utilizandose da mesma metodologia, podem mostrar resultados e modelos teóricos distintos. Por isso, a importância em dar continuidade a pesquisas sobre essa matéria.

\section{Referências}

1. Houaiss A, Villar MS. Dicionário Houaiss da língua portuguesa. Rio de Janeiro: Objetiva; 2009.

2. Przenyczka RA, Justino ET, Labronici LM, Chamma RC, Lacerda MR. Dilemas éticos que influenciam a prática da enfermagem: revisão sistemática. Rev Tenden Enferm Profis. 2011;3(2):415-8.

3. Dantas CC, Leite JL, Lima SBS, Stipp MAC. Teoria fundamentada nos dados aspectos conceituais e operacionais: metodologia possível de ser aplicada na pesquisa em enfermagem. Rev Latinoam Enferm. 2009;17(4):573-9.

4. Glaser BG. Advances in the methodology of Grounded Theory: theoretical sensitivity. $3^{\mathrm{a}}$ ed. California: The Sociology Press; 1978.

5. Decreto-lei n. 3.688, de 3 de outubro de 1941. In: Saraiva, Pinto ALT, Windt MCVS, Céspedes L, colaboradores. Código Penal: Constituição Federal e legislação complementar. 16ª ed. São Paulo: Saraiva; 2010. p. 150-9.

6. Lacerda MR, Przenyczka RA. Exercício (i)legal da enfermagem: a realidade do cuidador informal. Cogitare Enferm. 2008;13(3):343-51.

7. Conselho Federal de Enfermagem. Resolução Cofen 311 , de 8 de fevereiro de 2007. Aprova a reformulação do Código de Ética dos Profissionais de Enfermagem. Diário Oficial da República Federativa do Brasil, Brasília, DF, 13 fev. 2007. Seção 1, p. 81-3.
8. Paes MR, Maftum MA, Mantovani MF. Cuidado de enfermagem ao paciente com comorbidade clínico-psiquiátrica em um pronto atendimento hospitalar. Rev Gaúcha Enferm. 2010;31(2):277-84.

9. Rocha PCX, Moraes CL. Violência familiar contra a criança e perspectivas de intervenção do Programa Saúde da Família: a experiência do PMF/Niterói (RJ, Brasil). Ciênc Saúde Coletiva. 2011;16(7):3285-96.

10. Saraiva, Pinto ALT, Windt MCVS, Céspedes L, colaboradores. Código Penal: Constituição Federal e legislação complementar. 16a ed. São Paulo: Saraiva; 2010.

11. Valente SH, Teixeira MB. Estudo fenomenológico sobre a visita domiciliária do enfermeiro à família no processo de terminalidade. Rev Esc Enferm USP. 2009;43(3):655-61.

12. Hirschheimer MR, Constantino CF, Oselka GW. Consentimento informado no atendimento pediátrico. Rev Paul Pediatr. 2010;28(2):128-33.

13. Przenyczka RA, Lacerda MR. Dilemas éticos no ensino do cuidado domiciliar de enfermagem. Ciênc Cuid e Saúde. 2009;8(4):586-93.

14. Conselho Federal de Enfermagem. Lei $n^{\circ} 7.498$, de 26 de junho de 1986. Dispōe sobre a regulamentação do exercício da Enfermagem e dá outras providências. Diário Oficial da República Federativa do Brasil, Brasília, DF, 26 jun. 1986. Seção 1, p. 9.273-5. 